LETTERS

If you have a burning desire to respond to a paper published in the BJO, why not make use of our "rapid response" option? Log on to our website (www.bjophthalmol.com), find the paper that interests you, and send your response via email by clicking on the "eletters" option in the box at the top right hand corner.

Providing it isn't libellous or obscene, it will be posted within seven days. You can retrieve it by clicking on "read eletters" on our homepage.

The editors will decide as before whether to also publish it in a future paper issue.

\section{Acute angle closure glaucoma following the use of intranasal cocaine during dacryocystorhinostomy}

Many thousands of dacryocystorhinostomies (DCRs) are performed by ophthalmologists routinely without problems. Postoperative pain and nausea may wrongly be attributed to wound pain and post-anaesthetic nausea. Medical and nursing staff need to be aware of the potential for intranasal cocaine to precipitate acute angle closure glaucoma (AACG) We report two cases of AACG following the use of intranasal cocaine and subcutaneous lignocaine (lidocaine) with adrenaline during DCR surgery. We believe this to be the second report of such cases.

\section{Case report}

Two women, a 67 year old and a 75 year old, developed right sided AACG immediately after ipsilateral DCR surgery. Both patients were treated successfully for AACG. Cocaine is a known mydriatic and can induce angle closure glaucoma in predisposed individuals. Adrenaline in the local anaesthetic solution and intravenous atropine sometimes used during general anaesthesia are also known mydriatics.

We performed right sided external DCR surgery under general anaesthesia on both females. Regional preparation included a cocaine nasal pack ( $5 \%$ solution) and infiltration with lignocaine and adrenaline 1:200 000 at the proposed incision site subcutaneously. Preoperative intraocular pressures were within normal limits and there was no history of previous attacks of AACG or subacute angle closure glaucoma in either patient.

Overnight, both developed right eye pain and nausea and each was given analgesia and an antiemetic. Medical staff were not called to review the patients. The following morning, dressings were removed and a diagnosis of right sided AACG was made. Each patient had corneal oedema, a mid-dilated and nonreactive pupil, anterior chamber flare, and 360 degrees of angle closure on gonioscopy.
In the 67 year old, the intraocular pressure measured $18 \mathrm{~mm} \mathrm{Hg}$ in the right eye. This may be explained by spontaneous termination of the attack as a result of ciliary body ischaemia and suppression of aqueous secretion secondary to a high intraocular pressure overnight. ${ }^{1}$ In the left eye the intraocular pressure was $15 \mathrm{~mm} \mathrm{Hg}$ and gonioscopy revealed 270 degrees of grade I open angle, and 90 degrees of complete angle closure. Uneventful bilateral YAG iridotomy was performed.

In the 75 year old, the pressure was recorded as $57 \mathrm{~mm} \mathrm{Hg}$ in the right eye and only dropped to 39 after two doses of intravenous mannitol. Gonioscopy of the left eye revealed a 360 degree closable angle, grade 0 -I. Uneventful bilateral YAG iridotomy was performed. The corneal oedema resolved over the following week in both patients and visual field testing revealed no glaucomatous defect. Both patients require ongoing antiglaucoma therapy.

\section{Comment}

Cocaine is the only local anaesthetic to block noradrenaline re-uptake at the presynaptic adrenergic receptors. ${ }^{2}$ This single agent provides anaesthesia and haemostasis, making the use of cocaine desirable in lacrimal drainage surgery. Its use in DCR surgery was first described by Dupuy-Dutemps and Bourgener in $1922 .{ }^{3}$ We have routinely used cocaine for our DCR surgery, and emphasise the need to remain cognisant of its possible local and systemic side effects.

Cocaine is well absorbed from mucosal surfaces, reaching plasma levels similar to those achieved with intravenous administration. ${ }^{4}$ In adults, $50-95 \mathrm{mg}$ is a psychoactive dose. ${ }^{5}$ The maximum allowable dose is $3 \mathrm{mg} / \mathrm{kg}$; $1 \mathrm{~g}$ or 10 $\mathrm{ml}$ of a $10 \%$ solution represents a fatal dose for an adult. ${ }^{6}$ Usually, $80-200 \mathrm{mg}$ of cocaine is administered intranasally in DCR surgery Systemic cocaine toxicity has been reported in patients undergoing DCR surgery under general anaesthesia

AACG was described in the early 20th century with the use of cocaine as a corneal anaesthetic. More recently, a case of AACG associated with ipsilateral intranasal cocaine abuse was reported. ${ }^{7}$ In 1999, Hari et al described a single case of AACG following the use of cocaine in DCR surgery. ${ }^{8}$ Our two case reports strongly suggest that the use of intranasal cocaine to aid DCR surgery may precipitate AACG.

It is highly probable that the mydriasis which precipitated the attack of AACG was caused by the intranasal cocaine rather than the low concentration of subcutaneous adrenaline (1:200 000). There are two possible mechanisms of cocaine entry into the eye during DCR. Inadvertent transfer of cocaine from the surgeon's glove to the patient's conjunctival sac is possible if fresh gloves are not used between cocaine nasal packing and the infiltration of local anaesthetic. Alternatively, residual cocaine in the nasal cavity has direct access to the conjunctival sac after the lacrimal sac anastomosis in the DCR procedure.

Other potential causes of AACG include the mydriatic effect of the adrenaline in the lignocaine 1\%, 1:200 000 adrenaline, and atropine given intravenously during general anaesthesia.
At this concentration, subcutaneously administered adrenaline is unlikely to have precipitated the acute angle closure glaucoma. Atropine was not used during anaesthesia in either patient.

Given the apparent rarity of this proposed event, we cannot definitively conclude that lacrimal surgeons should change their approach to patients undergoing DCR surgery. However, it is important to remain cognisant of this potential complication and educate both nursing staff and medical trainees in ophthalmology and otolaryngology as to this potential complication. In addition, it would be reasonable to pad only the wound and not occlude the eye, which may have allowed the origin of the pain in our cases to be more readily identified. Postoperative pain and nausea following DCR surgery should not be automatically attributed to wound pain and post-anaesthetic nausea: AACG needs to be excluded. It may be prudent to assess routinely anterior chamber depth in high risk eyes before DCR surgery. If there is any suspicion of an eye anatomically predisposed to AACG both nursing and medical staff should be made aware of the potential complication. A prophylactic peripheral iridectomy may be indicated.

G A Wilcsek

Ocular Plastics Unit, Prince of Wales Hospital, University of New South Wales, Sydney, Australia

M J Vose

Ocular Plastics Unit, Manchester Royal Eye Hospital, Manchester, UK

I C Francis, S Sharma, M T Coroneo

Ocular Plastics Unit, Prince of Wales Hospital, University of New South Wales, Sydney, Australia

Correspondence to: Professor Minas T Coroneo Ocular Plastics Unit, Eye Clinic, Level 4, Prince of Wales Hospital, High St, Randwick, NSW, 2031 Australia; m.coroneo@unsw.edu.au

Accepted for publication 10 April 2002

\section{References}

1 Ritch R, Shields MB, Krupin Y. The glaucomas. 2nd ed. Vol 2. Missouri: Mosby, 1996:824-25

2 Sears ML, Tarkkanen A. Surgical pharmacology of the eye. New York: Raven Press, 1985:273

3 Dupuy-Dutemps, B. Cure de la dacrocystite chronique commune et du larmoiement par la dacrocystorhinostomie plastique. Bull Acad Med (Paris) 1921;86:293-5.

4 Schenck NL. Cocaine its use and misuse in otolaryngology. Trans Am Acad Ophthalmol Otolaryngol 1975:80:343-51

5 Mailer CM, Webster AC. Controlled sedation, sphenopalatine and nasociliary blocks, and bloodless flap suturing in dacryocystorhinostomy. Can J Ophthalmol 1982;17:189-93.

6 Meyers EF. Cocaine toxicity during dacryocystorhinostomy. Arch Ophthalmol 1980;98:842-3

7 Mitchell JD, Schwartz AL. Acute angle-closure glaucoma associated with intranasal cocaine abuse. Am J Ophthalmol 1996; 122:425-6.

8 Hari CK, Roblin DG, Clayton MI, et al. Acute angle closure glaucoma precipated by intranasal application of cocaine. J Laryngol Otol 1999;3:250-1. 


\section{Presumed hypersensitivity to minocycline and conjunctival infiltration}

Minocycline is a widely prescribed systemic antibiotic for acne. Its mechanism of action is complex and not only antimicrobial in nature. Other properties of minocycline include decreased chemotaxis of polymorphonuclear leucocytes, a modification of the complement pathways, an inhibition of the polymorphonuclear leucocyte chemotactic factor, and inhibition of lipase production in Propionibac terium acnes. ${ }^{1}$ In ophthalmology, minocycline is used for the treatment of rosacea. Although commonly considered to be a safe drug, there have been an increasing number of reports regarding systemic adverse reactions to minocycline during the past few years. ${ }^{2}$ Adverse effects to minocycline range from minor allergic reactions to death. ${ }^{2-9}$ The only ocular side effects reported to date have been cases of presumed minocycline induced scleral pigmentation. ${ }^{48}$ We report a case of conjunctival infiltrates, asthma exacerbation, and hypereosinophilia associated with the concurrent use of minocycline.

A 28 year old woman received oral minocycline $100 \mathrm{mg}$ once daily, for 29 days for the

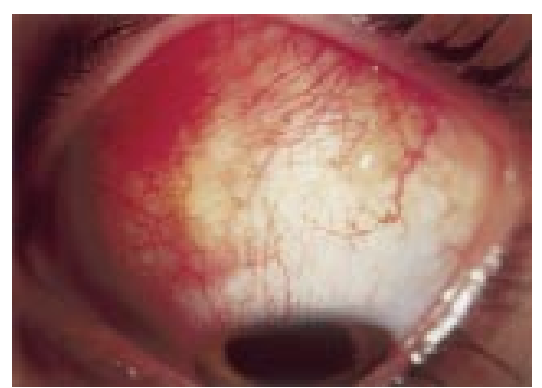

Figure 1 Slit lamp view of the conjunctival deep episcleral vessels.

\section{Case report} nodules with injection of the superficial and treatment of acne, without any other topical or systemic medication. She had a history of multiple allergies and asthma since early childhood, but no ocular history. During the first days of treatment, she developed asthenia, a mild fever of $38^{\circ} \mathrm{C}$, and severe asthma She was hospitalised. Thirty days after the beginning of minocycline treatment, she reported redness and burning of both eyes. Visual acuity was 20/20 in each eye. Several slightly elevated intraconjunctival nodules were seen in both eyes at the 12 o'clock position, with injection of the superficial and deep episcleral vessels (Fig 1). The tear film and the corneal epithelium were normal. There was no inflammation of the anterior chamber or of the posterior segment. Laboratory tests showed a severe eosinophilia: $2.12 \times 10^{9} / 1$ and $4.0 \times 10^{9} / 1$, at 15 and 30 days, respectively, after the onset of oral minocycline. Treatment of the patient's asthma included systemic prednisone initiated at $0.5 \mathrm{mg} / \mathrm{kg} /$ day. Cessation of minocycline led to rapid remission of asthma. Despite no topical treatment for her ocular findings, the conjunctival infiltration disappeared, and the ocular symptoms resolved. Laboratory tests showed a rapid decrease of the eosinophilia: $1.06 \times 10^{9} / 1$ and $0.7 \times 10^{9} / 1$ at 3 and 9 days, respectively, after cessation of minocycline.

A conjunctival biopsy was performed 39 days after the onset of minocycline treatment. Histopathology showed no modifications of the conjunctival epithelium, but oedema of the stroma. Vessels were surrounded with mononuclear lymphocytes and eosinophils. May-Grunwald-Giemsa staining confirmed eosinophilic polynuclear cells. Such inflammatory aggregates were also seen between vessels but not inside the vessel lumens (Fig 2).

\section{Comment}

Reports of adverse effects of minocycline include both hypersensitivity reactions and autoimmune disorders. ${ }^{25}$ Hypersensitivity reactions usually occur within a few weeks after the onset of treatment ${ }^{27}$ and may lead to exfoliative dermatitis, ${ }^{3} \quad$ eosinophilic pneumopathy, ${ }^{9}$ pericarditis, ${ }^{2}$ nephropathy, lymphadenopathy, ${ }^{2}$ pseudoinfectious reactions, ${ }^{2}$ and blood eosinophilia (that is $\left.>0.6 \times 10^{9} / 1\right)$. Autoimmune disorders usually present after exposure to minocycline for 1 year or $\operatorname{more}^{27}$ and include autoimmune hepatitis, ${ }^{7}$ lupus, ${ }^{7}$ and vasculitis. ${ }^{2}$ Pigmentations of the skin, fingernails, bones, and teeth have also been described in relation to the use of minocycline. Seven cases of scleral pigmentation presumed to have been induced by oral minocycline treatment have been reported..$^{4}$

Exacerbation of asthma and eosinophilia similar to our observation have been previously reported. ${ }^{9}$ The definite temporal association with conjunctival infiltration strongly suggested that minocycline therapy was the causative agent in our case. The patient's clinical findings did not show any abnormality of the superficial corneal epithelium near the limbus or any tear film abnormalities, as observed in a superior limbic keratoconjunctivitis-type reaction. Neither the transient nature of asthma and eosinophilia, nor the biopsy specimen was suggestive of ChurgStrauss disease in our patient. Different ocular manifestations, such as splinter haemorrhages and arterial emboli have been reported in the hypereosinophilic syndrome (eosinophilic counts greater than $\left.1.5 \times 10^{9} / 1\right)$, linked to chorioretinal thromboembolic disease. ${ }^{10}$ No thromboembolic manifestations were observed in the conjunctiva of our patient.

To our knowledge, our observation is the first report of a drug induced eosinophilic conjunctival infiltration.

C Parc, A P Brézin, I Nataf

Department of Ophthalmology, Cochin University Hospital, Paris, France

D Dusser Department of Pneumology, Cochin University Hospital, Paris, France

L Moachon Department of Pharmacology, Cochin University Hospital, Paris, France
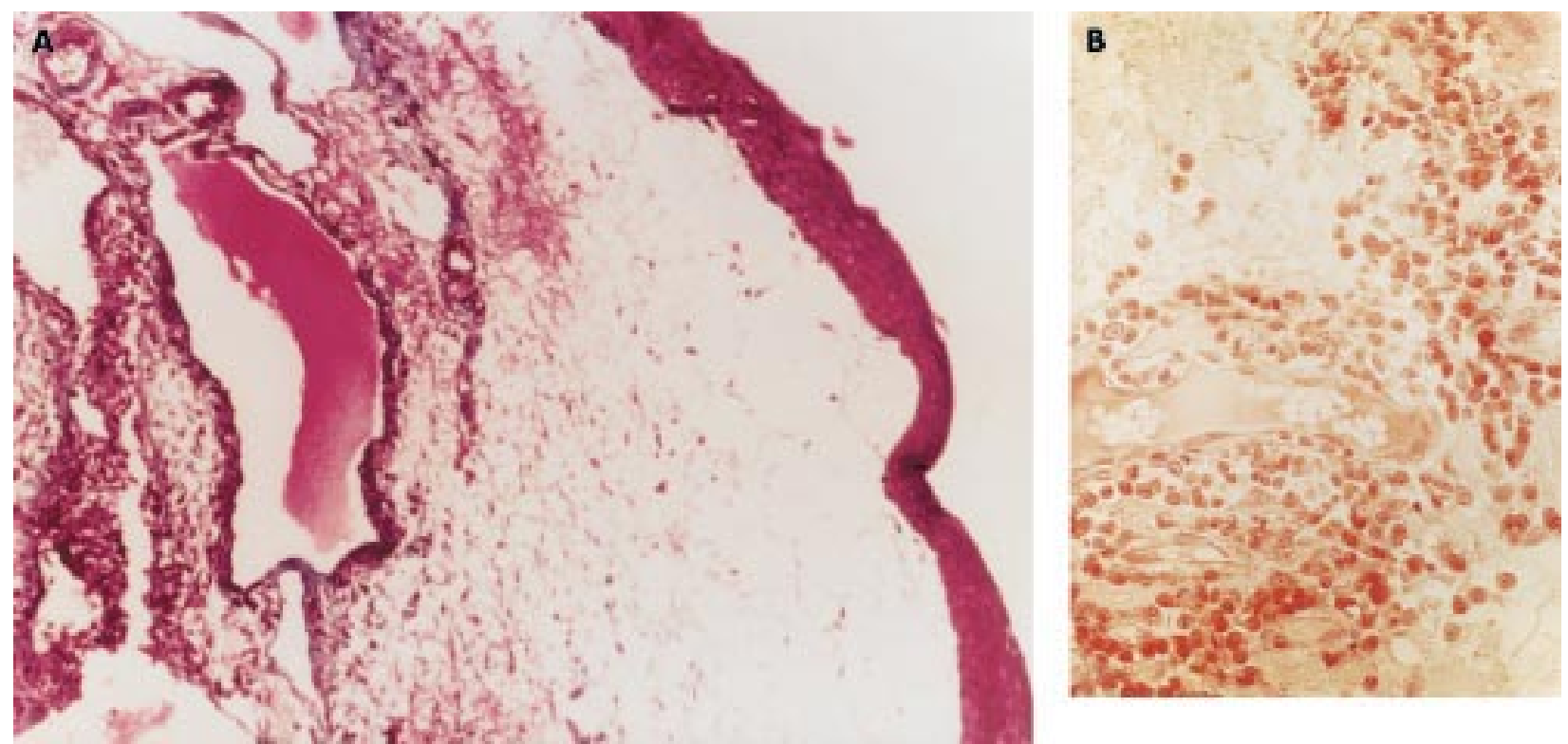

Figure 2 (A) Histopathological examination showed a normal conjunctival epithelium with oedema of the substantial propria. Dilated capillaries were surrounded by mononucleated inflammatory cells (haematoxylin and eosin, original magnification $\times 10$ ). (B) Histopathological examination showed mononucleated inflammatory cells surrounding a vessel in the substantial propria and eosinophilic infiltrates (haematoxylin and eosin, original magnification $\times 40$ ). 
F D'Hermies

Department of Pathology, Hôtel Dieu University Hospital, Paris, France

Correspondence to: Dr A P Brézin, Service d'Ophtalmologie, 27 rue du Faubourg Saint Jacques, 75679 Paris Cedex 14, France; antoine.brezin@cch.ap-hop-paris. Accepted for publication 1 May 2002

\section{References}

1 Meynadier J, Alirezai M. Systemic antibiotics for acne. Dermatology 1998;196:135-9.

2 Piette AM, Ramanoelina J, Gepner P, et al. Systemic reaction induced by minocycline treatment: a report of four patients and a review of the literature. Rev Med Interne 1999;20:869-74.

3 Gough A, Chapman S, Wagstaff K, et al. Minocycline induced autoimmune hepatitis and systemic lupus erythematosus-like syndrome. BMJ 1996:312:169-72.

4 Fraunfelder FT, Randall JA.

Minocycline-induced scleral pigmentation. Ophthalmology 1997; 104:936-8.

5 Lawrenson RA, Seaman HE, Sundstrom A, et al. Liver damage associated with minocycline use in acne: a systematic review of the published literature and pharmacovigilance data. Drug Saf 2000;23:333-49.

6 De Paz S, Perez A, Gomez M, et al. Severe hypersensitivity reaction to minocycline. J Invest Allergol Clin Immunol 1999;9:403-4.

7 Colmegna I, Perandones CE, Chaves JG. Minocycline induced lupus and autoimmune hepatitis. J Rheumato/ 2000;27: 1567-8.

8 Sabroe RA, Archer CB, Harlow D, et al. Minocycline-induced discoloration of the sclerae. Br J Dermatol 1996;135:314-16.

9 Sitbon O, Bidel N, Dussopt C, et al. Minocycline pneumonitis and eosinophilia. Arch Intern Med 1994;154:1633-40.

10 Chaine G, Davies J, Kohner EM, et al. Ophthalmic abnormalities in the hypereosinophilic syndrome. Ophthalmology 1982:89:1348-56.

\section{Importance of molecular testing in dominant optic atrophy}

Juvenile onset dominant optic atrophy (DOA) is the most common inherited optic atrophy with a variable prevalence of between 1 in 10000 (Denmark) and l in $50000 .{ }^{12}$ The majority of cases have been shown to have mutations in the OPAl gene on chromosome $3 .^{3-5}$ Reduced visual acuity of insidious onset, temporal pallor of the optic disc, centrocaecal scotoma, and generalised dyschromatopsia are the key clinical features. ${ }^{6}$ Recent studies, however, have shown that penetrance within families is much lower than first realised and the assignment of status using clinical criteria

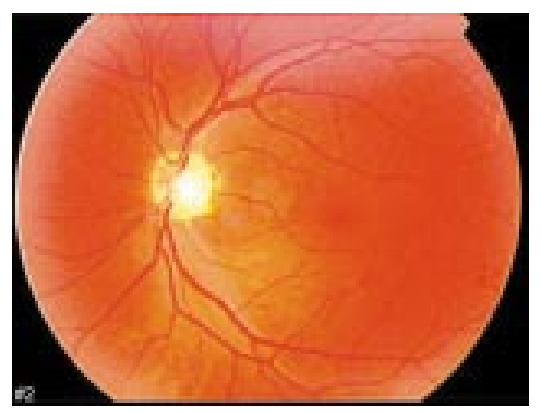

Figure 1 A fundus photograph of an affected patient with the OPAl gene mutation demonstrating temporal pallor as one of the distinguishing features of the condition.

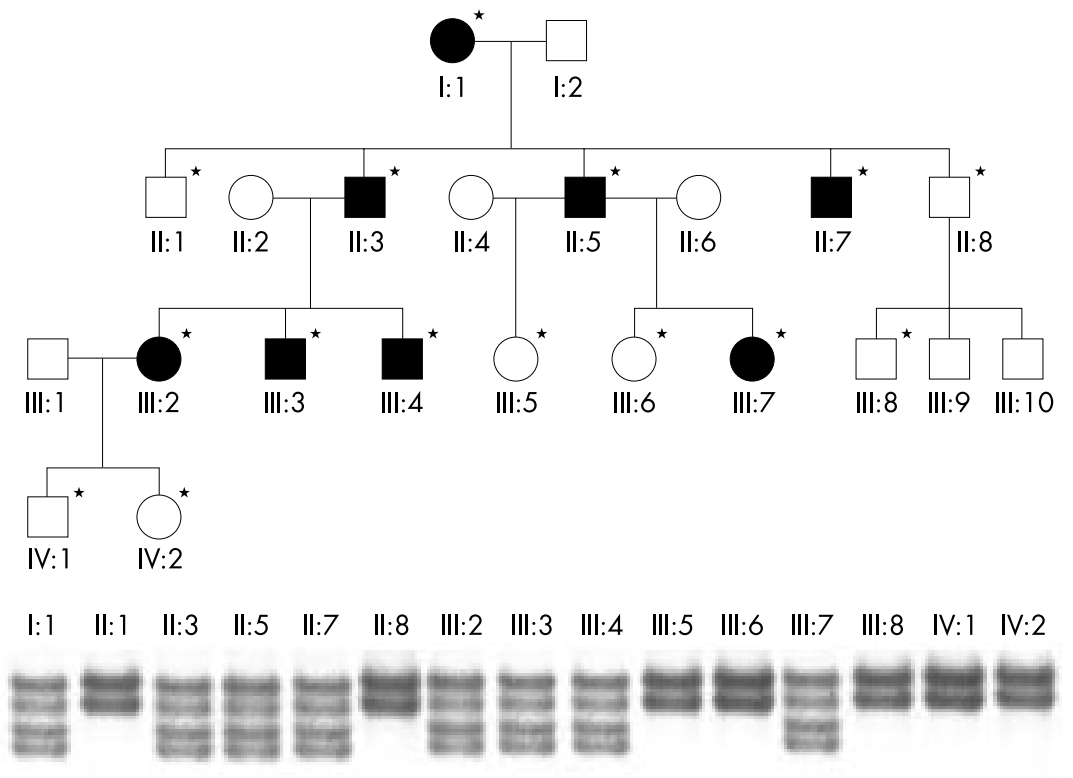

Figure 2 Family pedigree showing the dominant pattern of inheritance. * Members who underwent OPA 7 screening. Results of SSCP analysis of exon 27 are shown. Individuals with the 2708del (TTAG) mutation show a different banding pattern compared to the wild type sequence.

Table 1 Data showing the clinical results of visual acuity, colour vision, field analysis, and funduscopy from selected family members. The colour vision was tested for monocular and binocular tritan (blue-yellow), deutan (green), and protan (red) defects which were scored out of 10 plates

\begin{tabular}{|c|c|c|c|c|c|c|c|c|c|}
\hline \multirow[b]{2}{*}{ Individual } & \multirow{2}{*}{$\begin{array}{l}\text { Age } \\
\text { (years) }\end{array}$} & \multirow{2}{*}{$\begin{array}{l}\text { Age of } \\
\text { onset } \\
\text { (years) }\end{array}$} & \multicolumn{2}{|c|}{$\begin{array}{l}\text { Snellen visual } \\
\text { acuity }\end{array}$} & \multicolumn{2}{|c|}{$\begin{array}{l}\text { Centrocaecal } \\
\text { field defect }\end{array}$} & \multirow{2}{*}{$\begin{array}{l}\text { City University } \\
\text { binocular score }\end{array}$} & \multicolumn{2}{|c|}{$\begin{array}{l}\text { Temporal } \\
\text { pallor }\end{array}$} \\
\hline & & & RE & LE & RE & LE & & RE & LE \\
\hline $\mathrm{I}: 1^{*}$ & 73 & - & $6 / 18$ & $6 / 18$ & $N$ & $\mathrm{~N}$ & Tritan & $Y$ & $Y$ \\
\hline II: $3^{*}$ & 50 & 14 & $6 / 12$ & $6 / 18$ & Y & $Y$ & Tritan & Y & $Y$ \\
\hline II: $5^{*}$ & 49 & 20 & $6 / 12$ & $6 / 36$ & Y & Y & Tritan & $Y$ & $Y$ \\
\hline II:7 & 48 & - & $6 / 6$ & $6 / 6$ & $\mathrm{~N}$ & $\mathrm{~N}$ & Normal & $N$ & $N$ \\
\hline II:8 & 50 & - & $6 / 6$ & $6 / 6$ & $\mathrm{~N}$ & $N$ & Normal & $N$ & $\mathrm{~N}$ \\
\hline III:2* & 28 & - & $6 / 18$ & $6 / 18$ & $Y$ & $Y$ & Generalised & $Y$ & $Y$ \\
\hline III:3* & 23 & 7 & $6 / 36$ & $6 / 18$ & Y & $Y$ & Generalised & Y & $Y$ \\
\hline III: $4^{*}$ & 19 & 12 & $6 / 18$ & $6 / 12$ & Y & $Y$ & Normal & $Y$ & $\mathrm{Y}$ \\
\hline III:7* & 6 & 5.5 & $6 / 12$ & $6 / 9$ & $N$ & $\mathrm{~N}$ & Generalised & $Y$ & $Y$ \\
\hline
\end{tabular}

$\mathrm{Y}=\mathrm{Yes} ; \mathrm{N}=$ No. ${ }^{*}$ Classified as affected from clinical tests alone.

alone can result in misdiagnosis. ${ }^{5}$ This is well illustrated by the following family.

Fifteen family members were asked about perceived visual difficulties before measurement of visual acuity, colour vision (City University Test), and visual field analysis (Humphry 24-2). Fundal examination and photography were performed. Blood was taken for screening of the OPAI coding region using single stranded polymorphism analysis (SSCP) and automated DNA sequencing as previously described.

Seven family members were diagnosed as having optic atrophy from clinical tests alone (Fig 1). Where visual disability was recognised the age of onset ranged from 5.5 to 20 years (Table 1). Eight family members were classed as affected from molecular testing. All individuals exhibited an abnormal banding pattern on SSCP analysis of exon 27 (Fig 2). Sequencing revealed a four base pair deletion of TTAG at the start of exon 27 (nt2708 delTTAG). This deletion has been described previously and causes a frameshift resulting in two amino acid substitutions (Val903Gly, Arg904Asp) and a premature stop codon.

Dominant optic atrophy may be the result of mutations in genes other than OPA1. ${ }^{7}$ However, where DNA linkage analysis or mutation screening implicates the OPAl gene we feel that all family members should be offered molecular testing. In DOA it is well recognised that the clinical manifestation of the same mutation within a family can be very variable. ${ }^{6}$ This is well illustrated in Table 1. Genetic screening is the only reliable way of identifying individuals at risk of passing on defective genes to their offspring. In this family the combination of SSCP and DNA sequencing resulted in an alteration of the status of individual II:7 from unaffected to affected. If clinical tests alone had been relied upon, this individual would have most likely received incorrect genetic advice.

N Patel, A J Churchill Bristol Eye Hospital, Lower Maudlin Street, Bristol BS1 2LX, UK 
C Toomes, N J Marchbank, C F Inglehearn

Molecular Medicine Unit, University of Leeds, Leeds LS9 7TF, UK

N Foulds

St George's Hospital and School of Medicine, London SWI7 4QX, UK

A Moosavi, M Teimory

West Sussex Eye Unit, Worthing and St Richard's Hospital, West Sussex, BN 1 12DF, UK

Correspondence to: Dr Patel drnish1975@yahoo.com

Accepted for publication 1 May 2002

\section{References}

1 Kjer B, Eiberg $\mathrm{H}$, Kjer $\mathrm{P}$, et al. Dominant optic atrophy mapped to chromosome 3q. II. Clinical and epidemiological aspects. Acta Ophthalmol Scand 1996;74:3-7

2 Lyle WM. Genetic risks. Waterloo, Ontario: University of Waterloo Press, 1990.

3 Thiselton DL, Alexander C, Morris A, et al. A frameshift mutation in exon 28 of the OPA 1 gene explains the high prevalence of dominant optic atrophy in the Danish population: evidence for a founder effect. Human Genet 2001:109:498-502.

4 Delettre C, Griffoin J, Kaplan J, et al Mutation spectrum and splicing variants in the OPAl gene. Hum Genet 2001; 109:584-91.

5 Toomes C, Murton NJ, Mackey DD, et al. Spectrum, frequency and penetrance of OPA 1 mutations in dominant optic atrophy. Hum Mo Genet 2001;10:1369-78

6 Votruba M, Fitzke FW. Clinical features in affected individuals from 21 pedigrees with dominant optic atrophy. Arch Ophthalmol 1998;116:351-8.

7 Kerrison JB, Arnould OJ, Ferrazsallum JM. Genetic heterogeneity of dominant optic atrophy, Kjer type: identification of a second locus on chromosome 18q 12.2-12.3. Arch Ophthalmol 1999;117:805-10.

\section{Vanishing corneal epithelial crystals following thalidomide induced resolution of myeloma related paraproteinaemia}

A 64 year old man presented to the cornea service complaining of glare at night which had worsened over a 12 month period. He was found to have a pancorneal epithelial crystalline keratopathy with normal Snellen acuity (6/5 both eyes) and an otherwise unremarkable ocular examination (anterior chamber, lens, vitreous, and fundus). The crystalline keratopathy stretched from limbus to limbus and consisted of a homogeneous spread of tiny yellow crystals located in the epithelium and to a lesser extent the anterior corneal stroma. Two months later, following investigation for breathlessness he was diagnosed as suffering from multiple myeloma. Investigations revealed a raised plasma viscosity $(3.28$ $\mathrm{cp})$, an IgG- $\kappa$ paraprotein $(55.9 \mathrm{~g} / \mathrm{l})$, free immunoglobulin light chains in the urine (0.49 g/24 hours), a hypercellular bone marrow aspirate (70-80\% plasma cells), and a single lytic bone lesion in the left iliac crest.

He was entered into the MRC Myeloma Trial (Myeloma VII) and was randomised to receive $\mathrm{ABCM}$ (adriamycin, BCNU, cyclophosphamide, melphalan). However, his renal function rapidly deteriorated (creatinine 714 requiring plasma exchange. Seven courses of ABCM were completed before the myeloma reached plateau phase (paraprotein $27.1 \mathrm{~g} / \mathrm{l}$ ) at which point interferon alfa was begun as maintenance therapy. Seven months later, following episodes of bony pain requiring radiotherapy the myeloma relapsed (paraprotein
$38.3 \mathrm{~g} / \mathrm{l}$ ) and CIDEX (CCNU, idarubicin, dexamethasone) therapy was initiated. Six courses of CIDEX were completed until his paraprotein again plateaued (paraprotein 23.0 g/l)

Over the 6 month period following diagnosis visual acuity deteriorated to $6 / 9$ as the crystalline keratopathy worsened (Fig 1A, B). Epithelial debridement, followed by a bandage contact lens and topical antibiotic (while the epithelium healed) improved corneal clarity, visual acuity, and reduced glare for severa weeks before deterioration occurred once more. Over the next 2 years the epithelium was debrided alternately from one eye and then the other every 2-3 months and visual acuity was maintained at 6/6 to 6/9 Snellen.

Two months after completing CIDEX the myeloma relapsed again (paraprotein $38.7 \mathrm{~g} / \mathrm{l}$ ) and despite the use of weekly cyclophosphamide his renal function deteriorated and required haemodialysis. A month later a decision was made to try oral thalidomide therapy as the disease was progressing (paraprotein $52.8 \mathrm{~g} / \mathrm{l}$ ) and no longer responding to treatment. Initially he was started upon $50 \mathrm{mg}$ daily; however, a peripheral neuropathy developed when the dose was increased to $100 \mathrm{mg}$ daily and treatment was stopped for 3 weeks. The thalidomide was re-introduced in combination with dexamethasone, 4 days on 4 days off. The dexamethasone was slowly tailed off and the thalidomide reduced to $50 \mathrm{mg}$ on alternate days and latterly to $50 \mathrm{mg}$ twice weekly. Within 7 months of starting the thalidomide, the paraprotein had completely disappeared and the crystalline keratopathy had resolved (Fig 1C, D). Visual acuity at this time was 6/9 right eye and 6/18 left eye, due now in large part to the presence of early posterior subcapsular lens opacity.

\section{Commen}

Corneal crystalline deposits may occur in cystinosis, multiple myeloma, and other monoclonal gammopathies, infective crystalline keratopathy, Schyder's central crystalline dystrophy, Bietti's marginal crystalline dystrophy, gout, chronic renal disease, lipid keratopathy, and chrysiasis.

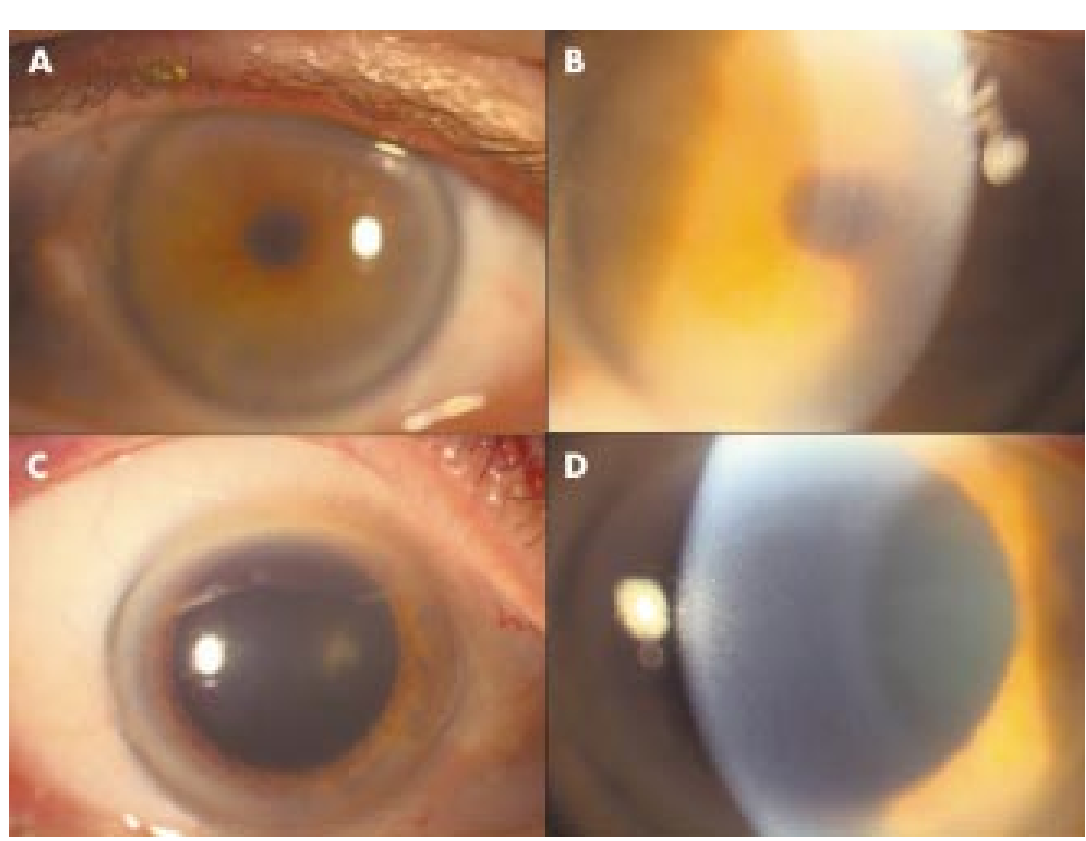

Figure 1 Slit lamp photographs of the left cornea. (A) Before thalidomide, low power. (B) Before thalidomide, high power.(C) After thalidomide, low power (pupil dilated). (D) After thalidomide, high power (pupil dilated).

Crystalline keratopathy occurs only rarely in association with multiple myeloma and monoclonal gammopathies. ${ }^{23}$ With the exception of Waldenstrom's macroglobulinaemia, the crystals are composed of IgG light chains (usually $\kappa^{3-6}$ but occasionally $\lambda^{7}$ ). The crystals may be deposited in the epithelium, as in the case we present, where they have been reported to lie both between and within the epithelial cells, ${ }^{467}$ and also within the cells of the corneal stroma, ${ }^{58}$ conjunctiva, and lens. ${ }^{367}$

It is not known why crystallisation occurs so infrequently in these conditions or why clinical appearances are so diverse, but factors including the structure, chemical properties and concentration of the paraprotein or its metabolites, ${ }^{8}$ and the local tissue environment are likely determinants. The effect of concentration cannot be disputed as the crystals tend to disappear as the paraprotein concentrations fall; however, the rarity of these corneal crystalline depositions suggests that the chemical and tertiary structures of the proteins or their metabolites is critically important.

Although it is reported that myeloma associated crystalline keratopathy can disappear in response to chemotherapy ${ }^{4}$ and plasma exchange $^{7}$ there are no previous reports of resolution following the use of thalidomide in refractory disease.

The mechanisms of action of thalidomide are complex and poorly defined but include immunomodulatory and anti-inflammatory effects, the modulation of TNF $\alpha$, T cell proliferation, increased production of IL2 and IFN- $\gamma$ and modulation of WBC migration and chemotaxis. The drug also has important anti-angiogenic effects which may be related to modulation of $\mathrm{TNF} \alpha$ or a direct inhibitory effect upon angioproliferation. Thalidomide is also sedative and hypnotic and its use for these latter effects gained infamy in the 1960s.

Used as single treatment for refractory or relapsed myeloma thalidomide represents one of the most significant advances in myeloma management in the past 20 years. Around a third to two thirds of patients are said to respond to thalidomide, typically within months. The response is marked by a significant $(25 \%$ to a least $90 \%)$ reduction in paraprotein and Bence-Jones proteins with some, 
like our patient, achieving complete remission. Although the anti-angiogenic effects of thalidomide are generally considered a key factor in the efficacy of the drug in multiple myeloma, the poor response of extramedullary plasmacytomas and the lack of correlation between bone marrow microvascular density and clinical response suggest that other actions of the drug may also be important. ${ }^{9}$

In summary, we report a case of a refractory multiple myeloma with associated corneal crystalline keratopathy in which resolution of the paraproteinaemia and corneal crystalline deposits occurred concurrently and following the initiation of thalidomide therapy. The report provides further support for the use of thalidomide in refractory multiple myeloma.

G N Shuttleworth, S D Cook Bristol Eye Hospital, Lower Maudlin Stree Bristol BS1 2LX, UK

J E Ropner

Gloucestershire Royal Hospital, Great Western Road, Gloucester GLI 3NN, UK

Correspondence to: G N Shuttleworth Singleton Hospital, Swansea SA280A, UK

Accepted for publication 1 May 2002

\section{References}

1 Miller KH, Green WR, Stark WJ, et al. Immunoprotein deposition in the cornea. Ophthalmology 1980;87:944-50.

2 Bourne WM, Kyle RA, Brubaker RF, et al Incidence of corneal crystals in the monoclonal gammopathies. Am J Ophthalmol 1989:107:192-3.

3 Steuhl KP, Knorr M, Rohrbach JM, et al. Paraproteinemic corneal deposits in plasma cell myeloma. Am J Ophthalmol

$1991 ; 111: 312-18$.

4 Perry HD, Donnenfeld ED, Font RL. Intraepithelial corneal immunoglobulin crystals in IgG-kappa multiple myeloma. Cornea 1993; 12:448-50.

5 Barr CC, Gelender H, Font RL. Corneal crystalline deposits associated with dysproteinemia. Report of two cases and a review of the literature. Arch Ophthalmol 1980;98:884-9

6 Klintworth GK, Bredehoeft SJ, Reed JW. Analysis of the corneal crystalline deposits in multiple myeloma. Am J Ophthalmol 1978;86:303-13

7 Firfin FC, Lee N, Ramsay R, et al. Visual loss caused by corneal crystals in myeloma: rapid improvement after plasma exchange and chemotherapy. Med J Aust 1979;29:677-8

8 Ormerod LD, Collin HB, Dohlman CH, et al. Paraproteinemic crystalline keratopathy. Ophthalmology 1988;95:202-12

9 Blade J, Perales M, Rosinol L, et al. Thalidomide in multiple myeloma: lack of response of soft tissue plasmacytomas. $\mathrm{Br} \mathrm{J}$ Haematol 2001;113:422-4

\section{Iris coloboma and a microdeletion of chromosome 22: $\operatorname{del}(22)(q 11.22)$}

A 22qll microdeletion is described in a girl with ocular coloboma associated with velocardiofacial syndrome (VCFS).

Microdeletion syndromes are a heterogeneous group of disorders caused by deletion of specific regions of chromosomal DNA that are not visible using standard chromosome analysis. ${ }^{1}$ Microscopic chromosome deletions are being recognised increasingly as a cause of congenital abnormality and clinical genetic syndromes. Laboratory confirmation of these conditions requires specialist molecular testing that must be requested on the basis of

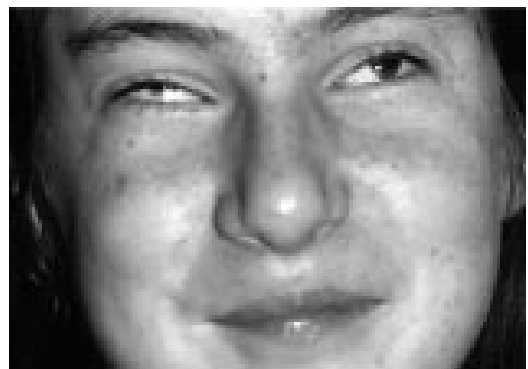

Figure 1 Bilateral iris coloboma with clinical microphthalmos in a girl with velo-cardiofacial syndrome. Note the upslanting and narrow palpebral fissures, wide nasal root and bridge, with prominent nose, and small mouth.

clinical suspicion. Del(22)(q1 1.22) microdeletion is among the most common of the microdeletion syndromes and is characterised by cardiac malformations (particularly outflow tract), craniofacial features, cleft palate, thymic hypoplasia, and hypoparathyroidism. The severity of the condition can be very variable and is now recognised as the basis of several independently described syndromes: DiGeorge syndrome (DGS), conotruncal face anomaly syndrome, and velo-cardiofacial syndrome (Shprintzen syndrome). ${ }^{2}$ The "velo" in VCFS refers to the palatal abnormalities such as cleft palate that are sometimes present. The characteristic facial appearance of $\operatorname{del}(22)(\mathrm{ql} l .22)$ is a prominent nose, broad nasal root, narrow palpebral fissures, and retrognathia. ${ }^{3}$ Recognised ocular features include retinal vascular tortuosity, small optic nerves, and narrow palpebral fissures. ${ }^{4}$ An iris coloboma has been described in one case of VCFS $^{5}$ and coloboma was listed as a rare feature in a series of cases of DGS

\section{Case report}

As part of a population based study of children with congenital anophthalmos, clinical microphthalmos, or iris coloboma (with or without fundus coloboma), we identified a teenage girl with bilateral iris coloboma, right fundus coloboma, left cataract, and clinical microphthalmos (Fig 1). On further examination she was found to have upslanting palpebral fissures, prominent nose, small mouth, dental crowding, unilateral deafness, arachnodactyly, second and third toe syndactyly (Fig 2 ), a ventriculoseptal defect (VSD) requiring surgical correction, and developmental delay. Both parents had no eye abnormality. A clinical diagnosis of VCFS was made and microsatellite analysis of this girl's DNA along with that of her parents confirmed a de novo deletion of the paternal 22q11.22 region. Two microsatellite markers (D22S944 and D22S264) within the common three megabase deletion interval demonstrated non-transmission of the paternal allele. In view of this unexpected diagnosis we analysed a further 21 study cases with structural eye malformations (mainly iris coloboma) where DNA was available from both parents. No additional $\operatorname{del}(22)(\mathrm{q} 11.22)$ cases were identified.

\section{Comment}

Here we report a girl with ocular coloboma and VCFS with a molecularly defined deletion of 22q11.22. Iris coloboma occurring in VCFS has been described once, but with no confirmation of a microdeletion.

The cat-eye syndrome (CES), a disorder with a variable pattern of multiple congenital

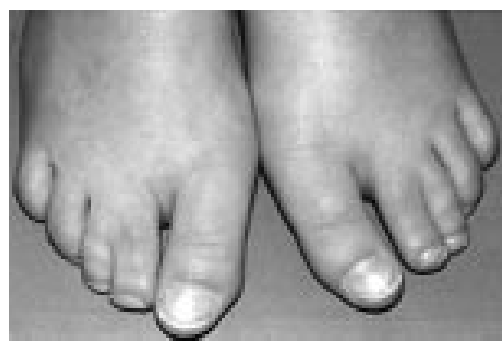

Figure 2 Second and third toe syndactyly in a girl with velo-cardiofacial syndrome and $\operatorname{del}(22)(q 11.22)$.

anomalies of which iris coloboma and anal atresia are the best known, is characterised cytogenetically by an extra bisatellited marker chromosome. ${ }^{6}$ This chromosome represents an inverted duplication of part of chromosome 22 (inv dup(22)). The CES critical region overlaps with the proximal area of chromosome 22q deleted in VCFS or DGS. Clearly, this region of chromosome 22 is significant in the aetiology of some ocular colobomas.

Ophthalmologists should be aware of these syndromes and the importance of recognising that eye anomalies such as iris coloboma might be the presenting feature of a systemic developmental disorder. Microdeletion syndromes should be considered even in the presence of a normal macroscopic chromosome report.

D A Morrison, D R FitzPatrick, B W Fleck Department of Clinical Genetics, Molecular Medicine Centre, Western General Hospital, Edinburgh EH4 2XU, UK

Correspondence to: Mr Morrison; danny@dannymorrison.co.uk

Accepted for publication 1 May 2002

\section{References}

1 Shapira SK. An update on chromosome deletion and microdeletion syndromes. Cur Opin Pediatr 1998; 10:622-7

2 Wilson DI, Burn J, Scambler P, et al. DiGeorge syndrome: part of Catch 22. J Med Genet 1993:30:852-6.

3 Kelly D, Goldberg R, Wilson D, et al. Confirmation that the velo-cardio-facial syndrome is associated with haploinsufficiency of genes at chromosome 22q11. Am J Med Genet 1993;45:308-12

4 Mansour AM, Goldberg RB, Wang FM, et al. Ocular findings in the velo-cardio-facial syndrome. J Pediatr Ophthalmol Strabismus 1987:24:263-6

5 Beemer FA, de Nef JJEM, Delleman JW, et al. Additional eye findings in a girl with the velo-cardio-facial syndrome. Am J Med Genet 1986:541-2.

6 Berends MJW, Tan-Sindhunata G, Leegte B et al. Phenotypic variability of cat-eye syndrome. Genetic Counselling $2001 ; 12: 23-34$

\section{Amniotic membrane transplantation for necrotising conjunctival ulceration following subconjunctival atropine injection}

Conjunctival necrosis has been previously reported after subconjunctival injection of several antimicrobial agents and corticosteroids. ${ }^{1-3}$ Atropine is used widely as a form of eyedrops for mydriasis, cycloplegia, and pain and inflammation control. We 

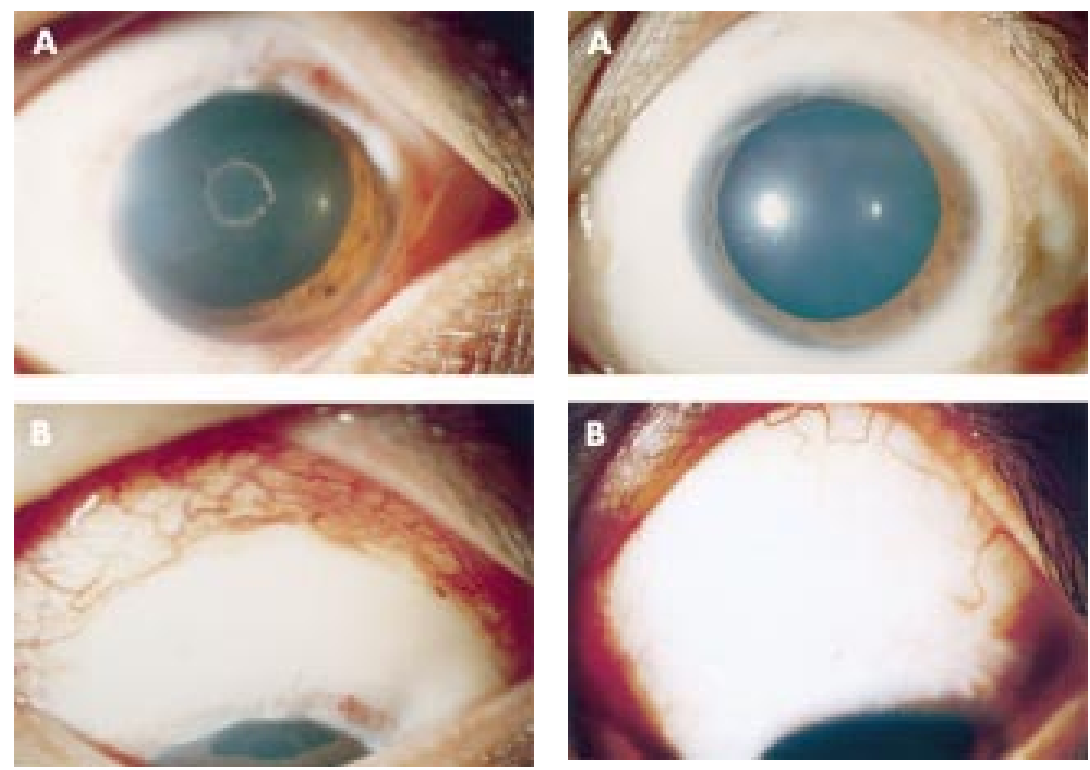

Figure 1 (A) The left eye showing large areas of necrosis developed around limbus. (B) Conjunctival necrosis and marked conjunctival injection in the superior bulbar conjunctiva.

describe a patient who developed severe conjunctival necrosis associated with scleral melting after subconjunctival atropine injection and which was treated by amniotic membrane transplantation.

\section{Case report}

A 30 year old male patient visited our clinic because of severe pain and redness in his left eye for a day. He had recently been diagnosed with uveitis associated with circular posterior synechiae in his left eye, and which was managed by his previous physician with a subconjunctival injection of $0.4 \mathrm{ml}$ of atropine ( 10 $\mathrm{mg} / \mathrm{ml}$, atropine sulphate, powder dissolved in saline, Mallinckrodt, St Louis, MO, USA) to lyse the posterior synechiae. Upon consultation at our institute, he was found to have marked conjunctival injection and chemosis all around the limbus. Three days after the atropine injection, large areas of necrosis developed around the whole limbus (Fig 1). White necrotic materials were noted on the underlying sclera and episclera. The underlying sclera in the inferotemporal bulbar conjunctiva showed a considerable area of melting $(2 \times 3 \mathrm{~mm})$.

We decided to manage the defect by amniotic membrane transplantation to the sclera because of the large extent of the defect and the scleral involvement. Debridement of the necrotic conjunctiva and episclera was done and the defect was covered with an amniotic membrane graft, which was obtained from women undergoing elective caesarean section and preserved at $-70^{\circ} \mathrm{C}$. The amniotic membrane was placed basement membrane side up and the excess membrane was trimmed The edges of them were sutured to the borders of the conjunctiva and the limus with 10-0 nylon. Topical $0.3 \%$ ofloxacin and $1 \%$ prednisolone acetate were prescribed every 2 hours postoperatively.

For the next week, the patient improved steadily, having less pain and redness. After a month, the necrotised defect was reepithelialised completely without inflammation, scar, or symblepharon formation (Fig 2). The eyedrops were tapered to four times daily for 2 weeks, twice daily for more 2 weeks, and then stopped.

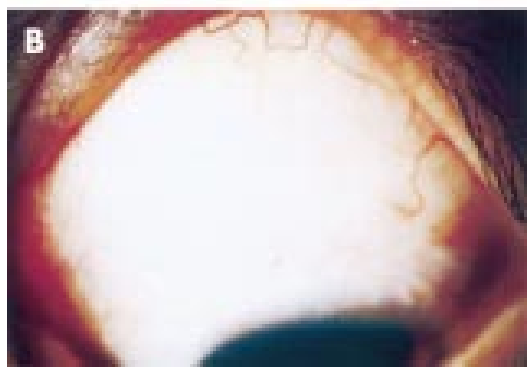

Figure 2 (A) Slit lamp photograph of left eye 1 month after treatment. The conjunctiva is completely healed. (B) The necrotised defect in the superior conjunctiva was re-epithelialised without any scar formation or symblepharon.

\section{Comment}

Subconjunctival atropine has been a useful management for the equine ophthalmic disorder including equine recurrent uveitis, many ulcerative keratopathies, and presurgical and postsurgical cataract extraction. ${ }^{4}$ In humans, however, the procedure of subconjunctival injection with atropine has been used infrequently. Our case shows that subconjunctivally delivered atropine should be approached with some degree of caution in humans.

The necrotising conjunctival ulceration in this case covered a large area and was also associated with scleral melting. It was rapidly healed after amniotic membrane transplantation without scleral perforation or symblepharon formation. Transplanted amniotic membrane has been known to provide a thick basement membrane to facilitate epithelial migration, play a part in decreasing inflammation and proteinase activity, and function as an anatomic barrier, keeping the adhesive surfaces apart. ${ }^{5-9}$ In our case, some combination of the mentioned characteristics would work for treating a severe necrotising conjunctival ulceration with the potential risk of symblepharon and perforation.

\section{K Y Seo, C Y Kim, J H Lee, J B Lee,} E K Kim

Institute of Vision Research, Department of Ophthalmology, Yonsei University College of Medicine, Seoul, Korea

Correspondence to: Eung Kweon Kim, MD, Institute of Vision Research, Department of Ophthalmology Brain Korea 21 Project, Division of Medica

Sciences, Yonsei University College of Medicine,

134 Shinchon-dong, Sodaemun-gu, Seoul, Korea,

Accepted for publication 8 May 2002

\section{References}

1 Kim T, Rapuano CJ, Rodman RC, et al. Conjunctival necrosis following the administration of subconjunctival corticosteroid. Ophthalmic Surg Lasers 1998;29:79-80. 120-752; eungkkim@yumc.yonsei.ac.kr
2 Zamir E, Pe'er J. Necrotizing conjunctival ulceration following subconjunctival depot methylprednisolone injection. Ophthalmic Surg Lasers 1999;30:565-6.

3 Johns KJ, O’Day DM. Pharmacologic management of keratomycoses. Surv Ophthalmol 1988;33:178-88.

4 Williams MM, Spiess BM, Pascoe PJ, et al. Systemic effects of topical and subconjunctival ophthalmic atropine in the horse. Vet Ophthalmol 2000:3:193-9.

5 Kim JC, Tseng SC. Transplantation of preserved human amniotic membrane for surface reconstruction in severely damaged rabbit corneas. Cornea 1995:14:473-84.

6 Tseng SCG, Prabhasawat P, Lee S. Amniotic membrane transplantation for conjunctival surface reconstruction. Arch Ophthalmol 1997; 124:765-74.

7 Hao Y, Hui-Kang D, Hwang D, et al. Identification of antiangiogenic and antiinflammatory proteins in human amniotic membrane. Cornea 2000; 19:348-52.

$8 \mathrm{Kim}$ JS, Kim JC, Na BK, et al. Amniotic membrane patching promotes healing and inhibits proteinase activity on wound healing following acute corneal alkali burn. Exp Eye Res 2000;70:329-37.

9 Dua HS, Azuara-Blanco. Amniotic membrane transplantation. Br J Ophthalmol 1999;83:748-52.

\section{Traumatic enucleation with chiasmal damage: magnetic resonance image findings and response to steroids}

Gouging has been reported throughout history and this case demonstrates it is still encountered in modern times. Its impact on visual function extends beyond the loss of an eye because of concomitant psychological morbidity.

\section{Case report}

We present a case report of a patient who suffered a traumatic enucleation. Our patient is 24 year old security manager who, while trying to prevent youths from harassing

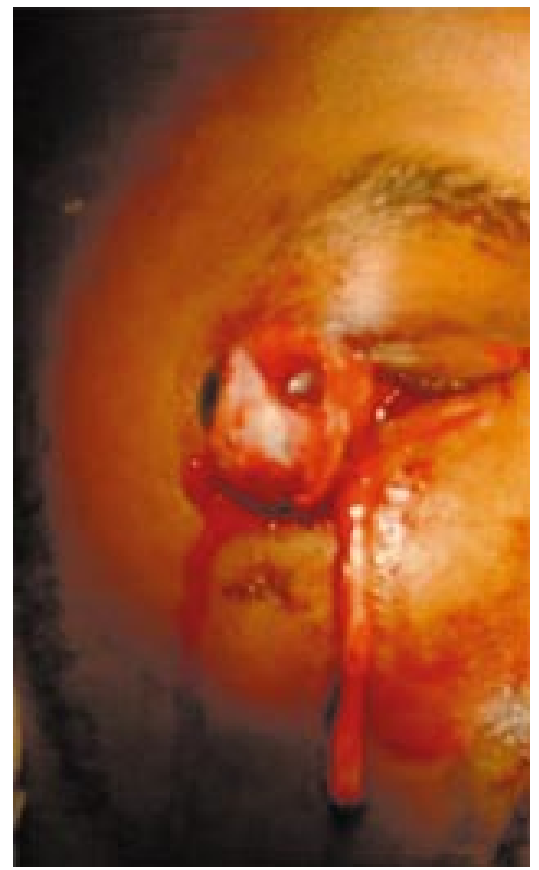

Figure 1 Photograph taken soon after assault showing the right gouged eye and avulsed optic nerve. 


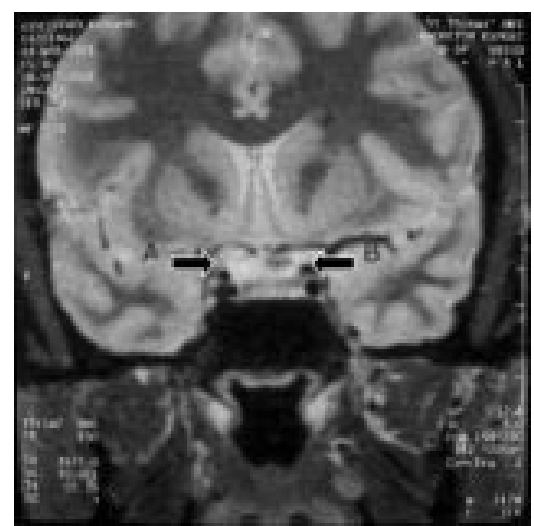

Figure 2 Arrow A shows high signal left hemichiasm and arrow $B$ shows normal right hemichiasm.

passengers on a bus, was assaulted by one of them. The attacker grabbed the patient from behind and attempted to insert his index fingers into each orbit, successfully on the right and the right eye was gouged out (Fig 1). He also sustained a minor head injury following some blows to the head but was not knocked out.

On examination the only remaining attachments to the globe were the lateral rectus and inferior oblique. His optic nerve was completely avulsed. Examination of his left eye revealed a temporal hemianopia. His vision was $6 / 6$. He was admitted and taken to theatre for a complete enucleation.

He had a Goldmann field performed which confirmed a temporal hemianopia. An magnetic resonance imaging (MRI) scan was carried out which showed swelling of the left side of the chiasm (Fig 2) He had a 3 day course of intravenous methylprednisolone after MRI findings. There was an interval of 12 days between the day of injury and commencing methylprednisolone.

His visual field test done at the end of the 3 day course of methylprednisolone showed a marked improvement in the inferotemporal quadrant (Fig 3). We presume the mechanism for chiasmal damage is traction on the chiasm. The MRI suggested oedema of hemichiasm perhaps interfering with function of the crossing fibres. Horton's recent findings suggest that Willebrand's knee of fibres may be an artefact and if so damage to crossing fibres in the stump of the avulsed nerve is unlikely to be an explanation for the field defect.

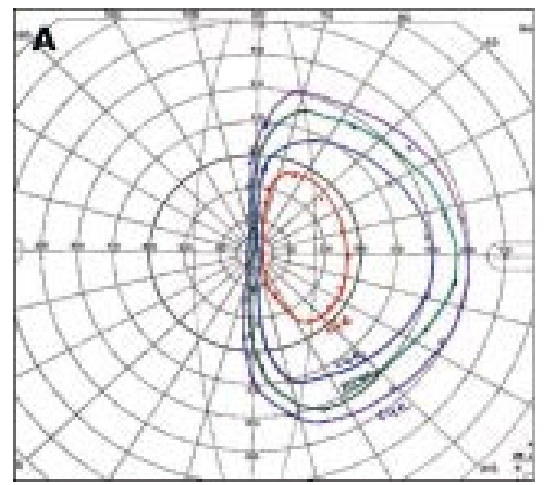

Figure 3 A left temporal hemianopia after injury (left) and the repeat Goldmann perimetry following pulsed methylprednisolone (right).

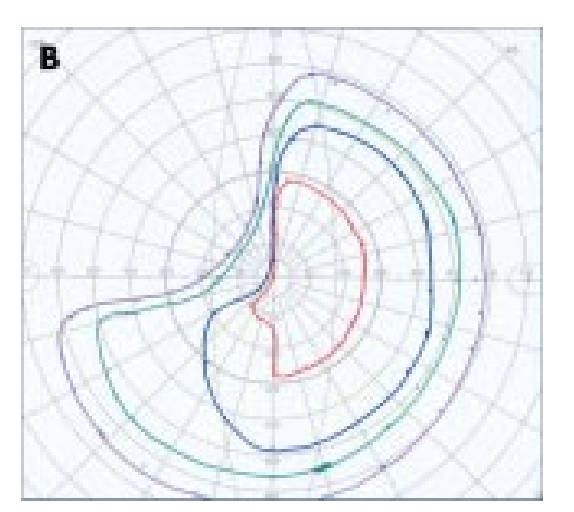

\section{Comment}

The incidence of traumatic enucleation reported by Erie and colleagues after performing a population based study in Minnesota from 1956-88 was 12 per 100000 but only one of these was due to an assault.

In our case the attacker aimed specifically for the victim's eyes. Bukhanovskhy and colleagues assessed the mental status of 10 eye gougers and found that four of these attackers were psychotic at the time of eye gouging. ${ }^{4}$ It is important to look not only at the psychology of the attacker but also the psychological impact on the victim. Our patient went to the psychiatry team weekly for counselling following the trauma.

Suzuki and colleagues reported that if the optic nerve transected is $4 \mathrm{~cm}$ or more in length than intracranial complications are likely. These include contralateral visual field loss (which was seen in our case) hypothalamic involvement, subarachnoid haemorrhage, and cerebrospinal fluid leakage. ${ }^{5}$

The use of steroids in traumatic optic neuropathy remains controversial. ${ }^{6}$ It is thought to restore altered vascular permeability and decreases the swelling of the optic nerve. We saw a marked improvement in the visual field which may be attributed to the steroids.

B Parmar, B Edmunds, G Plant Eye Department, St Thomas's Hospital, Lambeth Palace Road, London SE $17 \mathrm{NH}$, UK

Correspondence to: B Parmar; parmabina@hotmail.com

Accepted for publication 13 May 2002

\section{References}

1 Pillai S, Mahmood MA, Limaye SR. Complete evulsion of the globe and optic nerve. $\mathrm{Br} J$ Ophthalmol 1987;71:69-72.

2 Horton JC. Willebrand's knee of the primate optic chiasm is an artefact of monocular enucleation. Trans Am Ophthal Soc 1997;95:579-609.

3 Erie JC, Nevitt MP, Hodge D, et al. Incidence of enucleation in a defined population. $\mathrm{Am} J$ Ophthalmol 1992:113:138-44.

4 Bukhanovsky AO, Hempel A, Ahmed W, et al. Assaultive eye injury and enucleation. $J$ Am Acad Psychiatry Law 1999;27:590-602.

5 Suzuki N, Fujitsu K, Tanaka N, et al. Traumatic enucleation of the eyeball. Report of a case and considerations concerning the pathogenic mechanism of intracranial complications Acta Ophthalmol Scand 1999;77:340-2.

6 Levin LA, Beck RW, Joseph MP, et al. The treatment of traumatic optic neuropathy: the International Optic Nerve Trauma Study. Ophthalmology 1999;106:1268-77.

\section{Cyclodiode laser therapy to control intraocular pressure during pregnancy}

Controlling intraocular pressure (IOP) during pregnancy can be problematic because currently available topical ocular hypotensive agents are contraindicated or cautioned in pregnancy. ${ }^{1}$ We report the case of a patient with aphakic glaucoma controlled with topical agents, for whom we performed cyclodiode laser therapy, since she wanted to become pregnant. The use of cyclodiode laser therapy for this indication has not been described previously.

\section{Case report}

A 30 year old woman was referred to our specialist glaucoma clinic with a diagnosis of aphakic glaucoma in her right eye. She had a past ophthalmic history of chronic uveitis secondary to juvenile chronic arthritis, complicated right cataract surgery and subsequent aphakic glaucoma.

At the time of referral her visual acuities were $6 / 36$ in her right aphakic eye and 6/5 in the left eye. She had an IOP of $19 \mathrm{~mm} \mathrm{Hg}$ in her right eye and significant glaucomatous disc cupping (cup:disc ratio 0.85). Her right IOP was controlled with dorzolamide eye drops $2 \%$, carteolol eye drops $2 \%$, both twice a day, and latanoprost eye drops $0.005 \%$ at night. Our patient wanted to become pregnant but was justifiably concerned that the topical medication she was using might affect her pregnancy. It was decided that we would perform cyclodiode laser therapy on her right eye, under peribulbar anaesthesia, and stop her topical antiglaucomatous therapy. The first session of cyclodiode $(1500 \mathrm{~mW} \times 1500$ ms $\times 40$ shots over $360^{\circ}$ with 3 and 9 o'clock sparing) was unsuccessful and 6 weeks later her IOP was $33 \mathrm{~mm} \mathrm{Hg}$ on no ocular hypotensive therapy. The second session of cyclodiode therapy $(2000 \mathrm{~mW} \times 2000 \mathrm{~ms} \times 40$ shots $)$ was partially successful, the IOP being $22 \mathrm{~mm} \mathrm{Hg}$ 6 weeks later, although this had risen to 28 $\mathrm{mm} \mathrm{Hg}$ by 4 months. By this time our patient had become pregnant and it was felt that the IOP was still too high. A third attempt at lowering IOP by cyclodiode $(2000 \mathrm{~mW} \times 2000 \mathrm{~ms}$ $\times 40$ shots over $360^{\circ}$ ) was made, following which the IOP was persistently well controlled at $12-14 \mathrm{~mm} \mathrm{Hg}$.

\section{Comment}

The use of cyclodiode laser therapy to control IOP in women before and during pregnancy has not been described. It seems a rational choice in treating these patients since the use of topical antiglaucomatous therapy is either contraindicated or cautioned in pregnancy. ${ }^{1} \beta$ Blockers, sympathomimetics, carbonic anhydrase inhibitors, parasympathetomimetics, apraclonidine, and prostaglandin analogues have all been shown to have adverse effects in animal fetal models. ${ }^{12}$ Understandably, there have been no equivalent studies in the human fetus and resulting teratogenesis in laboratory animals cannot be extrapolated to humans. ${ }^{3}$ However, some specific examples of adverse effects related to specific topical medications have been quoted in the literature. ${ }^{245}$ Topical timolol has been shown to cause fetal cardiac arrhythmia and bradycardia. ${ }^{4}$ There has been one reported case that correlates the use of acetazolamide in early pregnancy with sacrococcygeal teratoma in the neonate. ${ }^{5}$ Prostaglandins are involved in the physiology of pregnancy and thus the use of latanoprost is not advised during pregnancy. ${ }^{2}$ 
Pregnancy is usually a period of lower IOP $^{6}$ and less therapy may be required than before gestation, although that was not the case with our patient. It could be argued that optic nerve damage over a 9 month period would be minimal such that a mildly raised IOP could be tolerated for the length of pregnancy. However, when glaucomatous damage is severe, it is generally accepted that a low target IOP should be attained.

There is a paucity of literature describing the use of local anaesthetics for ophthalmic procedures during pregnancy. However, in a large multicentre retrospective study, exposure to local anaesthetic during early pregnancy resulted in no increased incidence of fetal malformation. ${ }^{7}$ Our patient could have been offered augmented filtration or tube implantation surgery but cyclodiode was felt to be less invasive and, ideally, exposure to antimetabolites should be avoided in pregnancy. ${ }^{2}$

Cyclodiode is a safe and effective treatment to control IOP before and during pregnancy. The risk of topical medication to the fetus is eliminated and more complex surgical intervention with general anaesthesia is avoided.

\section{Wertheim, D C Broadway \\ Eye Department, Norfolk and Norwich University Hospital, Norwich NR4 7UZ, UK \\ Correspondence to: Dr Wertheim; drwertie@hotmail.com}

Accepted for publication 20 May 2002

\section{References \\ 1 British Medical Association and Royal Pharmaceutical Society of Great Britain. British National Formulary 39. London, 2000;478-82 \\ 2 Johnson SM, Martinez M, Freedman S. Management of glaucoma in pregnancy and lactation. Surv Ophthalmol 2001;45:449-54. \\ 3 Flach AJ. Glaucoma treatment and pregnancy. Arch Ophthalmol 1991;109:463 \\ 4 Wagenvoort AM, Van Vugt JMG, Sobotka \\ $M$, et al. Topical timolol therapy in pregnancy is it safe for the fetus? Teratology 1998;58:258-62 \\ 5 Worsham GF, Beckman EN, Mitchell EH Sacrococcygeal teratoma in a neonate. JAMA 1978;240:251-2. \\ 6 Avasthi P, Sethi P, Mithal S. Effect of pregnancy and labour on intraocula pressure. Int Surg 1976;61:82-4. \\ 7 Heinonen OP, Sloane D, Shapiro S. Birth defects and drugs in pregnancy. Littleton, $M A$ Publishing Science Group, 1977:357-65.}

\section{MAILBOX}

\section{Pupillary autonomic denervation and diabetes mellitus}

Recently, Cahill et at published a paper on pupillary autonomic denervation in diabetic patients. In our own recent study we can confirm the presence of a small dark adapted pupil size (DAP) before cardiovascular autonomic dysfunction is detected in patients with type 1 diabetes mellitus. ${ }^{2}$ We believe that this is an important observation, since autonomic alterations may cause an increase in mortality as repeatedly evidenced for cardiac autonomic neuropathy (CAN). ${ }^{3}$

In particular, we found a significantly reduced DAP in patients with normal ranges in high frequency waves of heart spectral analysis as a marker for cardiac parasympathetic nerve lesions and in variation coefficient of heart rate variability. We could also show significantly reduced pupillary responses to cocaine $4 \%$ eye drops in patients with CAN as a test for sympathetic nerve alterations. The DAP of patients with CAN did not yield significant differences from the age matched controls. Patients without any systemic diabetic long term complication defined as CAN, peripheral sensomotor neuropathy, retinopathy, and nephropathy had no significant differences in their DAP compared to the probands.

Thus, it is of interest if patients in this study with CAN also significantly differ in their pupillary responses to cocaine, and if patients without CAN possibly have other diabetic long term complications or increased glycosylated haemoglobin levels, which may correlate with the small DAP. ${ }^{4}$

Nevertheless, this study by Cahill et al also clearly indicates that screening for pupillary dysfunction is mandatory as early as possible to prevent the sequelae of other autonomic neuropathic disorders.

D Pittasch, R Lobmann, H Lehnert Department of Endocrinology and Metabolism, Magdeburg University Medical School, Germany

W Behrens-Bauman Department of Ophthalmology

Correspondence to: $\mathrm{H}$ Lehnert; hendrik.lehnert@medizin.uni-magdeburg.de

\section{References}

1 Cahill M, Eustace P, de Jesus V. Pupillary autonomic denervation with increasing duration of diabetes mellitus. Br J Ophthalmol 2001;85: 1225-30.

2 Pittasch D, Lobmann R, Behrens-Baumann W, et al. Pupil signs of sympathetic autonomic neuropathy in patients with type 1 diabetes. Diab Care 2002; (in press).

3 McNally PG, Lawrence IG, Panerai RB, et al. Sudden death in type-1 diabetes. Diab Obes Metabol 1999;1:151-8.

4 Sharma S, Hoskin-Mott A, Benstead T, et al. Correlation of the pilo-pupil ratio average, a new test for autonomic denervation, to the severity of diabetic retinopathy. Can J Ophthalmol 1997;32.170-4.

\section{Choroidal ischaemic infarction following ocular contusion with small framed spectacles: Hutchinson-Siegrist-Neubauer- syndrome}

We read with interest the article by Clarke $e t$ al. ${ }^{1}$ The authors describe their findings in a 79 year old aphakic woman with a so called nonpenetrating injury caused by compression with small framed spectacles. This type of injury is defined to be a contusion/closed globe injury. ${ }^{2}$

The authors presented a fundus photograph that they interpreted as a "choroidal rupture following blunt injury to the globe." In the superior hemisphere, there was a large temporally localised area with hypopigmentation and malperfusion of the choroid, corresponding to the segmental structure of the choroidal vasculature. ${ }^{3}$ However, the findings shown by the authors are more indicative of a segmental choroidal infarction (HutchinsonSiegrist-Neubauer-syndrome) ${ }^{4}$ A choroidal rupture typically presents as an arched choroidal defect at the posterior pole following indirect trauma or with other well defined defects in case of direct trauma. We found in all of our patients ( $7 \%$ of all severe contusions) with choroidal rupture a circumscribed and/or sickle shaped configuration. ${ }^{5}$
By contrast, this clinical picture of a segmental traumatic choroidal infarction was first described by Hutchinson in $1889 .{ }^{6}$ Siegrist confirmed this new disease in $1895 .{ }^{7}$ Neubauer observed in three patients the typical segmental choroidal atrophy with corresponding visual field defects. ${ }^{8}$ Lang and associates explained this severe complication following ocular contusion as follows: as a result of Bell's phenomenon and excessive eyelid squeezing, the globe is rotated upwards and moves backwards into the orbit between 0.7 to $1.7 \mathrm{~mm} .^{4}$ An occlusion or rupture of short ciliary arteries may result caused by sudden retroplacement of the globe into the orbit, ${ }^{4}$ which leads to the typical choroidal infarction of the corresponding vascular choroidal segments. ${ }^{34}$ We found HutchinsonSiegrist-Neubauer syndrome in $1 \%$ of all contusions of the Erlangen Ocular Contusion Registry. ${ }^{5}$

Our theory is supported with the recommendation of Vinger, who discussed the need for appropriate protective eyewear for all patients who had undergone intraocular surgery, especially in high risk patients-that is, after ICCE surgery.

A Viestenz, M Küchle Department of Ophthalmology, University Erlangen-Nürnberg, Schwabachanlage 6, D-91054 Erlangen, Germany

Correspondence to: Arne Viestenz, MD, Department of Ophthalmology, University Erlangen-Nuernberg, Schwabachanlage 6, D-91054 Erlangen, Germany; Arne.Viestenz@t-online.de

\section{References}

1 Clarke J, Newson R, Canning C. Ocular trauma with small framed spectacles. $\mathrm{Br} J$ Ophthalmol 2002:86:480.

2 Kuhn F, Morris R, Witherspoon CD, et al. A standardized classification of ocular trauma. Graefes Arch Clin Exp Ophthalmol 1996:234:399-403.

3 Hayreh SS. Segmental nature of the choroidal vasculature. $\mathrm{Br} J$ Ophthalmol 1975;59:631-48.

4 Lang GK, Lang GE, Ruprecht KW

Postkontusionelle ischämische Aderhautinfarkte (Hutchinson-SiegristNeubaver). Fortschr Ophthalmol 1984;81:75-9

5 Viestenz A, Küchle M. Retrospective analysis of 417 cases of contusion and rupture of the globe with frequent avoidable causes of trauma: the Erlangen Ocular Contusion Registry (EOCR) 1985-1995. Klin Monatsbl Augenheilkd 2001;218:662-9.

6 Hutchinson J Jr. VIII Disease of the choroid. 1. A form of retino-choroiditis due to contusion of the eye. Trans Ophthalmol Soc UK 1889;9:116-26.

7 Siegrist A. Traumatische Ruptur von Ciliararterien. Ann Suisses Sc Med 1895;3:554-71.

8 Neubaver H. Chorioretinopathia traumatica mit sektorenförmigem Gesichtsfeldausfall. Klin Monatsbl Augenheilkd 1957;131:487-500.

9 Vinger PF. Injury to the postsurgical eye. In: Kuhn F, Pieramici DJ, eds. Ocular trauma. Principle and practice. New York: Thieme, 2002:280-92.

\section{Anti-Acanthamoeba efficacy in contact lens disinfecting systems}

Hiti et al produced an interesting study investigating the susceptibility of three strains of Acanthamoeba to a PHMB (polyhexamethylene biguanide) based multipurpose solution (MPS), a one step peroxide system $\left(3 \% \mathrm{H}_{2} \mathrm{O}_{2}\right)$, and a two step peroxide system $\left(0.6 \% \mathrm{H}_{2} \mathrm{O}_{2}\right)$. However, no comment was made regarding 
the choice of strains tested, only one of which (A castellanii 4CL) was typical of those that cause keratitis in humans. This isolate belongs to genotype T4, the predominant genotype in Acanthamoeba keratitis. ${ }^{23}$ Their second strain (A hatchetti 11DS) is of T6 genotype, which, with the exception of one incident, ${ }^{4}$ has not previously been reported as causing keratitis. The third strain (A lenticulata 72/2) belongs to genotype $\mathrm{T} 5,{ }^{23}$ and as the authors themselves state "has not been reported to cause Acanthamoeba keratitis." Although testing of all three strains was of interest to the microbiologist, the only result that can be extrapolated to clinical practice and be of clinical relevance to the contact lens wearer is that for $A$ castellanii (4CL).

The majority of two step peroxide systems currently available contain 3\% hydrogen peroxide. The authors tested a weak peroxide solution $(0.6 \%$ or $6000 \mu \mathrm{g} / \mathrm{ml})$, but gave no comment as to why they chose a system with such a low active concentration. The two step system was, however, found to be effective neat after an 8 hour exposure, but not as a 1:2 dilution $(3000 \mu \mathrm{g} / \mathrm{ml})$. This result was to be expected as Zanetti et al, in 1995, demonstrated that a 1:2 dilution of a 3\% hydrogel peroxide solution killed cysts of $A$ castellanii after a 9 hour exposure, but that a 1:10 dilution $(0.3 \%$ or $3000 \mu \mathrm{g} / \mathrm{ml})$ had lost its cysticidal effect.

The MPS tested was designed for use with rigid gas permeable lenses and contained PHMB at a concentration of $0.0005 \%(5 \mathrm{ppm}$ or $\mu \mathrm{g} / \mathrm{ml}$ ). This is higher than that found in the majority of soft lens MPS, which contain $0.0001 \%$ PHMB. As the minimum trophozoite amoebicidal concentration (MTAC) of PHMB is $1 \mu \mathrm{g} / \mathrm{ml}$ and the minimum cysticidal concentration (MCC) is $3 \mu \mathrm{g} / \mathrm{ml},{ }^{6}$ the solution has performed as expected against the clinically relevant strain. Also, a recent study by our group 7 testing the efficacy of a variety of MPS for soft lenses, including one containing $0.0005 \%$ PHMB, found this concentration to be cysticidal after the manufacturer's recommended disinfection time of 4 hours. A reduced effect occurs with $0.0001 \%$ PHMB.

One step peroxide systems have been shown to be less effective than two step systems, as the peroxide in the one step solutions is rapidly neutralised. ${ }^{8}$ Therefore, again, the results for the one step peroxide system were as expected. In addition, a recent cohort study of CL wearers in Hong Kong has shown that lens storage cases were more likely to yield "no bacterial growth" and less likely to yield "heavy bacterial growth" if MPS were used in preference to one step peroxide solutions. ${ }^{9}$

The results for all three solutions when tested against clinically relevant strains of Acanthamoeba were as expected. The authors concluded by recommending the two step peroxide system $\left(0.6 \% \mathrm{H}_{2} \mathrm{O}_{2}\right)$ for overnight soaking of contact lenses as an effective disinfectant against Acanthamoeba. However, antimicrobial efficacy is not the only factor that should be considered when advising a CL wearer about a disinfecting solution. Thought must be given to ease of use and personal compliance. It has been suggested that the introduction of MPS has led to a reduced incidence of the infection since 1995. ${ }^{10}$ Although MPS may not be as cysticidal as a two step peroxide system, compliance by the CL wearer is higher. In addition, the MPS kills bacteria and fungi within lens cases which reduces growth factors for Acanthamoeba.

CL wearers should practise good hygiene, cases should be changed monthly and only filled with sterile solutions such as MPS - tap water should never come into contact with a lens storage case. Scrubbing of cases, as recommended by the authors, is not required with frequent (monthly) replacement. If such measures are followed then the lens case is kept free of Acanthamoeba. ${ }^{11}$ The use of MPS with PHMB at $0.0001 \%$ is trophozoiticidal at 24 hours with partial effect against cysts. ${ }^{7}$ If two step hydrogen peroxide solutions are used instead, then the peroxide should be at a concentration of $3 \%$ and not $0.6 \%$ as recommended by the authors as co-contaminating bacteria, which may be present in the lens case, can produce catalase which aids neutralisation of the active peroxide.

T K Beattie, A Tomlinson Department of Vision Sciences, Glasgow Caledonian University, Cowcaddens Road Glasgow G4 OBA, UK

D V Seal Applied Vision Research Centre, City University,
Northampton Square, London EC IV OHB, UK

Correspondence to: Tara Beattie t.k.beattie@gcal.ac.uk

References

1 Hiti K, Walochnik J, Haller-Schober EM, et al. Viability of Acanthamoeba after exposure to a multipurpose disinfecting contact lens solution multipurpose disinfecting contact lens solution Ophthalmol 2002;86: 144-6.

2 Stothard DR, Schroeder-Diedrich JM, Awwad $\mathrm{MH}$, et al. The evolutionary history of the genus Acanthamoeba and the identification of eight new $18 \mathrm{~S}$ rRNA gene sequence types. J Eukaryot Microbiol 1998:45: 45-54.

3 Schroeder JM, Booton GC, Hay J, et al. Use of subgenic 18 S ribosomal DNA PCR and sequencing for genus and genotype identification of acanthamoebae from humans with keratitis and sewage sludge. J Clin Microbiol 2001:39:1903-1 1.

4 Walochnik J, Haller-Schroeber E-M, Kolli H, et al. Discrimination between clinically relevant and non-relevant Acanthamoeba strains isolated from contact lens-wearing keratitis patients in Austria. J Clin Microbiol 2000;38:3932-6.

5 Zanetti S, Fiori PL, Pinna A, et al. Susceptibility of Acanthamoeba castellanii to contact lens disinfecting solutions. Antimicrob Ag Chemother 1995;39:1596-8.

6 Hay J, Kirkness CM, Seal DV, et al. Drug-resistance and Acanthamoeba keratitis: the quest for alternative antiprotozoal chemotherapy. Eye 1994:8:555-63.

7 Beattie TK, Tomlinson A, McFayden, et al. Application of a most probable number method of organism enumeration to determine the amoebicidal activity of multi-purpose solutions. Invest Ophthalmol Vis Sci 2002;43:3099.

8 Hughes R, Kilvington S. Comparison of hydrogen peroxide contact lens disinfection systems and solutions against Acanthamoeba polyphaga. Antimicrob Ag Chemother 2001;45:2038-43.

9 Houang E, Lam D, Fan D, et al. Microbia Keratitis in Hong Kong - relationship to climate, environment and contact lens disinfection. Trans R Soc Trop Med Hyg 2001;95:361-7.

10 Stevenson RWW, Seal DV. Has the introduction of multi-purpose solutions contributed to a reduced incidence of Acanthamoeba keratitis in contact lens wearers? Contact Lens Anterior Eye 1998;21:89-92.

11 Seal DV, Dalton A, Doris D. Disinfection of contact lenses without tap water rinsing - is it effective? Eye 1999;13;226-30.

\section{NOTICES}

\section{Technology for Vision 2000}

The latest issue of Community Eye Health (No 42 ) focuses on technology and training, with an editorial by Catherine Cross, chairperson of the International Agency for the Prevention of Blindness (IAPB). For further information please contact: Journal of Community Eye Health, International Centre for Eye Health, Institute of Ophthalmology, 11-43 Bath Street, London ECIV 9EL, UK (tel: + 44 (0)20 7608 6910; fax: +44 (0)20 7250 3207; email: eyeresource@ucl.ac.uk; website: www.jceh.co.uk). Annual subscription (4 issues) UK£25/US\$40. Free to workers in developing countries.

\section{International Centre for Eye Health}

The International Centre for Eye Health has published a new edition of the Standard List of Medicines, Equipment, Instruments and Optical Supplies (2001) for eye care services in developing countries. It is compiled by the Task Force of the International Agency for the Prevention of Blindness. Further details: Sue Stevens, International Centre for Eye Health, 11-43 Bath Street, London EC1V 9EL, UK (tel: +44 (0)20 7608 6910; email: eyeresource@ucl.ac.uk).

\section{Second Sight}

Second Sight, a UK based charity whose aims are to eliminate the backlog of cataract blind in India by the year 2020 and to establish strong links between Indian and British ophthalmologists, is regularly sending volunteer surgeons to India. Details can be found at the charity website (www.secondsight.org.uk) or by contacting Dr Lucy Mathen (lucymathen@yahoo.com).

\section{SPecific Eye ConditionS (SPECS)}

SPecific Eye Conditions (SPECS) is a not for profit organisation which acts as an umbrella organisation for support groups of any conditions or syndrome with an integral eye disorder. SPECS represents over fifty different organisations related to eye disorders ranging from conditions that are relatively common to very rare syndromes. We also include groups who offer support of a more general nature to visually impaired and blind people. Support groups meet regularly in the Boardroom at Moorfields Eye Hospital to offer support to each other, share experiences and explore new ways of working together. The web site www.eyeconditions.org.uk acts as a portal giving direct access to support groups own sites. The SPECS web page is a valuable resource for professionals and may also be of interest to people with a visual impairment or who are blind. For further details about SPECS contact: Kay Parkinson, SPECS Development Officer (tel: +44 (0)1803 524238; email: k@eyeconditions.org.uk; www.eyecon ditions.org.uk).

\section{The British Retinitis Pigmentosa Society}

The British Retinitis Pigmentosa Society (BRPS) was formed in 1975 to bring together people with retinitis pigmentosa and their families. The principle aims of BRPS are to raise funds to support the programme of medical research into an eventual cure for this hereditary disease, and through the BRPS welfare service, help members and their families copy with the everyday concerns caused by retinitis pigmentosa. Part of the welfare service is the telephone helpline $(+44$ (0) 1280860363 ), which is a useful resource 
for any queries or worries relating to the problems retinitis pigmentosa can bring. This service is especially valuable for those recently diagnosed with retinitis pigmentosa, and all calls are taken in the strictest confidence. Many people with retinitis pigmentosa have found the Society helpful, providing encouragement, and support through the Helpline, the welfare network and the BRPS branches throughout the UK. (tel: +44 (0)1280821 334; email: lynda@brps.demon.co.uk; web site: www.brps.demon.co.uk)

\section{Introductory Course in Osteo-odonto-keratoprosthesis (OOKP)}

The University of Brighton Postgraduate Medical School is holding an introductory course in osteo-odonto-keratoprosthesis (OOKP) 20-21 November 2002 in the New Seminar Room, Sussex House, Brighton \& Sussex University Hospitals Trust in Brighton. The course will comprise of a variety of lectures with live surgery, two way audio and video links (Stage 1 and Stage 2 OOKP surgery), and examination of patients. Further details: Mrs Erica Strange, University o Brighton, Postgraduate Medical School, Falmer Campus, Brighton, East Sussex BNl 9PH, UK (tel: +44 (0)1273 644 005; fax: $+44 \quad(0) 1273644 \quad 002$; email: e.strange@brighton.ac.uk).

\section{3rd Annual Conference and Dinner Glaucoma Society (UK \& EIRE)}

The 23rd Annual Conference and Dinner of the Glaucoma Society will be held on Thursday 21 November 2002,8.30am to $5.00 \mathrm{pm}$ at the Central Conference Centre, London. The Annual Dinner is from 6.30pm to $10.00 \mathrm{pm}$ at The Royal College of Surgeons, London. Conference charges: $£ 60$ members; $£ 80$ nonmembers. Price entitles delegates to refreshments, lunch, abstract book, programme, and annual dinner. (Maximum number of places 250-apply now to secure your place). Further details: Janet Flowers, Administrator, 29 Quarry Hill, Grays, Essex, RM17 5BT, UK (tel/fax: 01375 383172; email: glausoc@ukeire.freeserve.co.uk).

Retinal Detachment Course with international faculty and case presentations preceding Vitrektomie-Kurs-Wetlab

The Retinal Detachment Course with international faculty and case presentations and Vitrektomie-Kurs-Wetlab will be held 13 February 2003 (in English) and 14-15 February 2003 (in German) respectively, at Verwaltungsgebaeude der KA Rudolfstiftung, 1030 Vienna, Boerhaavegasse 8a, Austria. Further details and registration: Firma Askin \& Co, Albert-Schweritzer-Gasse 6, A-1140 Vienna, Austria (tel: +43 (1) 97988 44; fax:+43 (1) 9798846 ).

\section{Detachment Course with} international faculty on: Retinal and Vitreous Surgery with Case Presentations preceding Retina Meeting

The detachment course with international faculty on: Retinal and Vitreous Surgery with Case Presentations and the Retina Meeting will be held 14-15 March 2003 and 16 March 2003 respectively, in Mexico City, Mexico. Further details: Scientific programme: Prof Ingrid Kreissig, University of Tuebingen, Schleichstr. 12, Breuningerbau, 72076 Tuebingen, Germany (tel: +49 7071 295209; email: ingrid.kreissig@med.uni-tuebingen.de). Local organisation: Prof. Quiroz-Mercado, Prof. Munoz, and Prof Gonzalez "Hospital Luis Sanchex Bulnes", Asociacion para Evitar la Ceguera en Mexico Vicente Garcia Torres \#46, Coyoacan, Mexico DF 04330 (fax: + 5255 5659 5928; email: retinamex@yahoo.com).

\section{6th Annual Meeting of German Ophthalmic Surgeons}

The 16th Annual Meeting of German Ophthalmic Surgeons will be held 8-11 May 2003 in Nürnberg, Germany, Messezentrum. Organised by the Professional Association of German Ophthalmologists Ophthalmic Surgery Group the conference will cover cataract surgery, refractive surgery, glaucoma surgery, vitreoretinal surgery, corneal surgery, eye surgery in developing countries, and orbita, lacrimal and lid surgery. Further details: MCN Medisinische Congress organisation Nürnberg AG, Zerzabelshofstr 29, 90478 Nürnberg, Germany (tel:+49 911 3931621; fax: +49 911 3931620; email: doc@mcnag.info; web site: www.doc-nuernberg.de).

\section{Detachment Course with international faculty on: Retinal and Vitreous Surgery with Case Presentations preceding the Annual Meeting of Iranian Society of Ophthalmology}

The detachment course with international faculty on: Retinal and Vitreous Surgery with Case Presentations preceding Annual Meeting of Iranian Society of Ophthalmology will be held on 29-30 November 2003 and 1-4 December 2003 respectively, at the Razi Conference Center, Hemmat Hyw, Tehran, Iran. Further details: Scientific programme: Prof Ingrid Kreissig, University of Tuebingen, Schleichstr. 12, Breuningerbau, 72076 Tuebingen, Germany (tel: +49 7071 295209; email: ingrid.kreissig@med.uni-tuebingen.de). Local organisation: Dr Arman Masheyekhi, Dr Siamak Moradian, Dept of Ophthalmology, Labbanfinejad Medical Center, Pasdaran Ave, Boostan 9, Tehran, 16666, Iran (fax: +9821 254 9039; email: labbafi@hotmail.com). 